\title{
A history of the development of the mathematics and statistics support community in the United Kingdom. Part 1: From alpha to sigma
}

\author{
Duncan Lawson, sigma, Coventry University, Coventry, UK. Email: $\underline{m t x 047 @ c o v e n t r y . a c . u k}$
}

\begin{abstract}
In terms of the history of mathematics higher education, mathematics and statistics support (MSS) is a very recent development, existing as a formal feature for less than 50 years. However, in this short time, MSS has displayed its own characteristics. A particularly notable feature of MSS in the United Kingdom (and in other countries) has been the way in which practitioners have collaborated with each other, almost from the outset. This collaboration has led to the creation of a community (the sigma network) with a written constitution and formal membership. This two-part article traces the history of the development of the MSS community in the UK from its earliest incarnations to the present day. The first part of the article reviews the period from the early 1990 s to 2005 during which time the key events were the rise and demise of the Mathematics Support Association and the creation of sigma, Centre of Excellence in University-wide Mathematics and Statistics Support.
\end{abstract}

Keywords: Mathematics and statistics support, community of practice, Centres of Excellence in Teaching and Learning.

\section{Personal Introduction}

This article springs from a keynote presentation that I gave at the Continuing Excellence in Teaching and Learning in Mathematics, Statistics and Operational Research (CETL-MSOR) conference in Dublin in September 2019. After the presentation, several delegates were kind enough to suggest that the material I had presented, particularly the "historical" information merited being written up and published. I set out to write an "objective history" of the mathematics and statistics support (MSS) community in the UK. However, I found that, as someone whose career coincides almost exactly with the time period under consideration and who has been actively involved in the MSS community for most of that time, it was very difficult to separate facts from personal experience from personal opinion. The result is perhaps a somewhat unusual article for this journal: a personal perspective on the subject rather than an objective record. However, I believe that this still has value and interest for the readers of MSOR Connections and, if you are reading this, then presumably the Editors shared this opinion.

\section{Alpha - origins (pre-1993)}

It is hard to date precisely when mathematics support (MS) began in the UK (Note that here I refer to mathematics support and not mathematics and statistics support; in the beginning statistics support was not considered separately). This imprecision stems from determining which practices count as MS and which do not. For example, one of the earliest formally organised MS provisions was the BP Mathematics Support Centre at Coventry Polytechnic, which began in 1991. However, prior to this at the same institution, there had been a service called "Maths workshop" where a few members of academic staff made themselves available during a few lunchtimes a week for students to come and ask them questions about mathematics. This activity was not part of the formal educational provision of the department, rather it was something the colleagues involved undertook "voluntarily" because they thought it would be beneficial for some students. 
The BP Mathematics Support Centre at Coventry was established by Glyn James in 1991 following a successful bid to the BP [British Petroleum] Engineering Education Fund. In one way, this can be viewed as an outcome of collaboration and community, as Glyn James had met, through the SEFI (European Society for Engineering Education) Mathematics Working Group, Milton Fuller from the Mathematics Learning Centre at Central Queensland University (CQU). The two developed a longstanding co-operative working relationship with Milton Fuller spending some time as a visiting academic in the Mathematics Department in Coventry. Milton Fuller was a proponent of mathematics support (Fuller, 2002) and it seems likely that his experience influenced the proposal that Glyn James made to BP. According to Dzator and Dzator (2020), the Mathematics Learning Centre at CQU was established in 1984 and was the first such centre in Australia.

The motivation for establishing MS at Coventry Polytechnic and other institutions in the UK was the high failure rates on engineering degree courses. These high rates were often attributed to the mathematical component of the course. There was a feeling amongst academics that incoming students were not sufficiently well-prepared mathematically for study in higher education (see, for example, Hymas (1994) and Barnard \& Saunders (1994)). In 1995, two influential reports Tackling the Mathematics Problem (LMS, IMA \& RSS, 1995) and The changing mathematical background of engineers (Sutherland and Pozzi, 1995) were published by influential professional bodies and learned societies. These reports catalogued some of the difficulties being encountered by lecturers "at the chalk face" and introduced the phrase The Mathematics Problem as a recognised shorthand for the underpreparedness of many new undergraduates for the mathematical demands of their higher education study. A more complete discussion of the development of the Mathematics Problem can be found in Lawson, Grove and Croft (2019).

Although it took until 1995 for professional bodies and learned societies to issue their reports, academic colleagues had been introducing measures to address the Mathematics Problem for some time before then and MS, as exemplified by the BP Mathematics Support Centre, was one such measure.

\section{Beta - the Mathematics Support Association (1993 - 1999)}

It is perhaps a little unfair to categorise the Mathematics Support Association (MSA) as a beta-test version of later mathematics support networks since it functioned for six years as a formal community for those involved in MS. However, whilst it was valuable to its members, there is evidence that it did not achieve the widespread level of engagement across the HE sector that is necessary to sustain such a community of practice.

On 23 May 1993 the $1^{\text {st }}$ National Conference in Mathematics Support in Further and Higher Education took place at the University of Luton. This conference was organised by two colleagues from the University of Luton, lan Beveridge and Rakesh Bhanot. One outcome of the conference was the establishment of the MSA which aspired to produce annually two issues of the Mathematics Support Newsletter. There was an annual subscription of $£ 15$ for institutions to be members of the Association and, in return, institutions received a hard copy of each issue of the newsletter and discount for all delegates attending future conferences.

A report by Lane (1994) in the first issue of the Newsletter describes the conference in some detail, including giving a delegate list. Lane describes his overall impression of the conference as "dedicated enthusiasts, struggling to cope with a desperate situation which is getting worse each year. Usually with inadequate resources." (Lane, 1994, p.14). There were 58 named attendees at the first conference, 27 were from higher education institutions, 29 from further education colleges and two others. The 27 from higher education included 14 from new universities (i.e. former polytechnics which had recently become universities in 1992 with the abolition of the so-called binary 
divide), eight from colleges of higher education (i.e. institutions not having full university title), two from the Open University and three from pre-92 universities. This lack of involvement in the Association from pre-92 universities, and particularly the Russell Group ${ }^{1}$, seemed to continue throughout the lifetime of the association.

There was an article about mathematics support at Imperial College (Kent, Ramsden and Wood, 1996) in the double $4^{\text {th }}$ and $5^{\text {th }}$ issue, but otherwise involvement from the Russell Group was very limited. This limited involvement of Russell Group institutions and indeed pre-92 universities more generally may have been due to the inclusion of further education providers. These universities may not have wanted the needs of their students to have been seen to be similar to those of students in further education. Even with the universities that were part of the MSA, there was a tension between further education and higher education in terms of the nature of the provision. Bowers highlighted the different interpretations of what constituted a mathematics workshop, stating "some colleges use the 'total' workshop approach where the whole student experience in certain maths courses consists of more or less flexible attendance in a large open learning resources centre. At the other extreme, some institutions consider a workshop to be a handful of nominated hours per week when a lecturer is free to help students with problems" (Bowers, 1994, p.2). The latter part of this description is reminiscent of the aforementioned Maths Workshop at Coventry Polytechnic. Although not explicitly mentioned by Bowers, his extremes almost certainly represented, on the one hand, provision in further education and, on the other, provision in higher education. The MSA perhaps contained two sub-communities that grew apart rather than together: one where mathematics support was seen as the principal form of delivery (a replacement for traditional approaches to teaching, possibly because it was cheaper) and one where it was regarded as additional to standard teaching (because standard teaching was not delivering high enough pass rates).

Although each issue of the Newsletter contained a good range of articles with contributors from many different institutions, the initial intention of two issues per year was not often met. A total of eight editions (one being a double issue) were published over 6 years ${ }^{2}$. A second conference took place in Luton, once again organised by lan Beveridge, in September 1995, although discussion of this in the Newsletter was limited to a quarter page anonymous report in the 1996 issue. A third conference took place in Loughborough in 1998, organised by Tony Croft, but no report of this conference was published in the newsletter. Furthermore, there is very little evidence in the Newsletters of collaboration between the conferences. In the $3^{\text {rd }}$ issue, there is a proposal for a project to develop a Maths Support Handbook (Samuels, 1995), there is further discussion in the $4^{\text {th }} / 5^{\text {th }}$ double issue and then notification in the $6^{\text {th }}$ issue that the funding application for this project had been rejected. This appears to be the only attempt at a multi-partner collaboration in MS during this period.

Ian Beveridge was undoubtedly the central individual in the MSA. In addition to organising the first conference, he was Editor of all issues of the Newsletter, authored several articles in the Newsletter (including the first survey of the extent of mathematics support provision in further and higher education, (Beveridge and Bhanot, 1994)), acted as membership secretary and organised the second conference again at Luton, in 1995. Other individuals are named as Editorial Assistants of the Newsletter (including David Bowers who was also a regular contributor of articles), but most of

1 The Russell Group is an association of large research intensive universities which describe themselves as leading UK universities, see https://russellgroup.ac.uk/

${ }^{2}$ All issues of the Mathematics Support Newsletter can be accessed on the sigma Network website at http://www.sigma-network.ac.uk/maths-support-association-archive-1994-1999/ 
these took this role for only one issue. Only Tony Croft, who was Editorial Assistant for the final four issues, had any longevity in the role. Indeed the reliance of the Newsletter on one individual (and his family) can be seen most starkly in the credits for the double $4^{\text {th }}$ and $5^{\text {th }}$ issue which lists the following as responsible for its production: Editor: lan Beveridge; Editorial Assistants: Bill Beveridge, Patricia Murdie; Newsletter designer: Martin Beveridge.

The MSA disappeared abruptly following the publication of the $9^{\text {th }}$ issue of the Newsletter in Autumn 1999. The final issue gives no hint of the impending demise. Indeed, it proudly announces a new initiative: the development of a website for the MSA at www.luton.ac.uk/mathssupport. This newsletter does not look like it is from an association in decline. However, no further record of the Mathematics Support Association can be found and the reasons for its disappearance are a mystery. It is possible that, for some unknown reason, lan Beveridge retired suddenly from higher education and there was no structure in place to find someone to take his place as the driving force of the MSA; however this is only speculation. Nonetheless, this unexplained closure of the MSA highlights the dangers of a community being over-reliant on a single individual.

\section{Epsilon - the void (1999-2005)}

In two-phase (solid-gas) flow, the letter epsilon is sometimes used to represent the void fraction (Grace, 2016); with the disappearance of the MSA, an organised MS community ceased to exist creating a void fraction of one. However, during this void period, there was considerable activity in MS and several activities and projects of this period paved the way for what would follow in terms of large-scale cross-sector and indeed, international, collaboration and community building in MS.

In 2000, the Engineering Council published the influential report Measuring the Maths Problem (Hawkes and Savage, 2000). The first two recommendations of this report were:

1. Students embarking on mathematics-based degree courses should have a diagnostic test on entry.

2. Prompt and effective support should be available to students whose mathematical background is found wanting by the tests.

This validated the practice in many institutions of initial diagnostic testing, with follow-up provision of MS and was used in negotiations in several institutions to secure funding for MS.

At this time, improving learning and teaching in higher education was becoming an important priority for the Higher Education Funding Council for England (HEFCE) and the funding councils of the other nations of the UK. In 2000, the funding councils introduced the Learning and Teaching Support Network (LTSN). The LTSN's first strategic aim was

"To be the primary information and advice resource for all academic and related staff in HE on generic and subject specific learning and teaching practices." 1

The LTSN consisted of 24 subject centres offering subject-specific expertise relating to learning and teaching and a generic centre providing information that crossed subject boundaries. The subjectfocus of the subject centres, where typically most of the staff were current academic staff seconded on a fractional basis, gave them credibility with many academic colleagues across the sector. In the

${ }^{1}$ https://web.archive.org/web/20040817074717/http://www.Itsn.ac.uk/index.asp?id=8 
mathematical sciences, the subject centre was called the LTSN Maths, Stats and OR (MSOR) Network. This Network initiated MSOR Connections.

Although the MSOR Network had a brief that was very much wider than that of the now defunct MSA (i.e. supporting all aspects of teaching in mathematics, statistics and operational research, not just MS), it had something that the MSA never had: money. And MS practitioners had the opportunity to access this funding. One of the programmes that the MSOR Network operated was the mini-project scheme; in this scheme, an open call was issued for projects related to learning and teaching, with up to $£ 5,000$ per project available.

In 2001, Duncan Lawson (Coventry) and Tony Croft (Loughborough) secured funding from the MSOR Network for a mini-project entitled Evaluating and enhancing the effectiveness of mathematics support centres. The project set out to survey the extent of mathematics support across the sector, the first such survey since Beveridge and Bhanot (1994) and the first ever focused solely on higher education. Ninety-five institutions replied to the survey with 46 reporting that they had some form of mathematics support provision (Lawson, Halpin and Croft, 2001). The survey was followed up by visits to a selection of institutions where interviews with staff and students were carried out. Students were asked to identify the good and bad points of the mathematics support provision. One-to-one tutor support came top of the lists of both good and bad points. Eighty-eight percent of students identified it as a good point; with $71 \%$ identifying that there was not enough of it as a bad point (Lawson, Halpin and Croft, 2002). The final stage of this project was the publication of a practical handbook Good practice in the provision of mathematics support centres (Lawson, Croft and Halpin, 2003).

The LTSN was not the only source of funding available at this time. The Fund for the Development of Teaching and Learning (FDTL) was jointly funded by HEFCE and the Department for Employment and Learning (Northern Ireland) and had much larger budgets available. FDTL operated in phases following on from Quality Assurance Agency Subject Reviews. Mathematics was included in the subjects able to access funding in Phase 4. A consortium, led by Mike Savage (Leeds) including the Educational Broadcasting Services Trust and Tony Croft and Duncan Lawson, secured $£ 500,000$ funding from FDTL4 for a project National Mathematics Support for the School/University Interface. Subsequently a further $£ 500,000$ was given to this project by the Gatsby Foundation to extend the range of resources produced. This project developed the mathtutor resources (www.mathtutor.ac.uk), originally a set of 7 DVD-ROMs covering key mathematics topics at the school/university interface. The resources were built around high quality videos providing teaching, supported by text-based documents and interactive exercises. As technology advanced during the lifetime of the project, the use of DVDs as a delivery vehicle was replaced by streaming over the internet. The mathtutor resources were (and remain) freely available for use in MS in universities throughout the UK.

A smaller but nonetheless significant collaboration led by Tony Croft in association with Duncan Lawson and Mike Savage was the virtual UK Mathematics Learning Support Centre: mathcentre (www.mathcentre.ac.uk). A total of $£ 80,000$ was gathered for this project from a range of LTSN Subject Centres that had an interest in mathematics (in addition to the MSOR Network, funding was also provided by the Engineering, Physical Sciences and Material Sciences subject centres and the generic centre). The aim of this project was to gather into one place an extensive set of resources for MS. These resources would be freely accessible to anyone who wanted them. The project targeted both academic staff who provided MS, to save them having to develop their own resources, and students, particularly those in institutions that did not have a MS provision in their institution. This website remains a well-used repository of MS resources. 
Although none of the above-mentioned projects had community building as one of their aims, these projects laid important foundations for the future. In particular:

1. They demonstrated the value of cross-university working (not least, in securing funding consortia were preferred to single institution proposals, particularly for large amounts);

2. The principle of benefit to the community/sector not just the institutions of the project team was firmly established;

3. The difference that the availability of finance can make to "getting things done".

\section{5. sigma - Centre for Excellence (2005)}

The Centre for Excellence in Teaching and Learning (CETL) programme was HEFCE's largest ever investment in Teaching and Learning, the total funding in this programme was $£ 315$ million. Individual centres could bid for up to $£ 2$ million of capital funding and annual revenue funding of $£ 0.5$ million for five years (a total of $£ 4.5$ million). Bids could be from single institutions or from consortia with universities limited, according to their size, in the number of single institutions and consortialeading bids they could submit. The programme had two primary aims: to reward excellent teaching practice, and to further invest in that practice to deliver substantial benefits to students, teachers and institutions.

The bidding process required applicants to establish the excellence of their existing provision and then to outline a plan of activity that would produce benefits for students, teachers and institutions. However, there was very little emphasis in the guidance on these benefits being beyond the institutions hosting the CETLs. In final evaluations of the CETLs, the lack of benefit beyond the host institutions is one of the major criticisms (SQW, 2011, Ramsden, 2012).

Loughborough and Coventry Universities submitted a consortia-bid for a Centre for Excellence in University-wide mathematics and statistics support. A number of points from this proposal are worth explicitly mentioning:

1. The proposal identified the different needs of statistics support as compared to mathematics support;

2. Despite the bidding guidance not stressing the need to explore benefit to the sector, this proposal had considerable focus on developing MSS in other institutions;

3. An early activity in the programme was the establishment of a mathematics support centre at Leeds University (where there was no centre) and through this to develop a blueprint for use in other institutions wishing to set up their own MSS provision;

4. A commitment to provide funding, to be allocated by competitive bidding, to establish MSS in two further institutions with no such provision;

5. Opportunities for MSS practitioners to have funded secondments to Loughborough or Coventry to work on a MSS project.

This proposal was successful and the collaborative CETL came into being in September 2005. It was soon apparent that most of the other CETLs had short, snappy names, usually clever acronyms, and that the title Centre for Excellence in University-wide mathematics and statistics support whilst descriptive of the Centre was something of a mouthful. At an early team meeting involving colleagues from both institutions, several hours of brainstorming focusing on meaningful acronyms had drawn a blank when the suggestion of sigma emerged. This was not an acronym, but a symbol that has meaning in both mathematics (upper case, summation) and statistics (lower case, standard deviation). In view of the difference in case between the usage in mathematics and statistics it was decided not to use the Greek letter but the word sigma itself as the name of the CETL, although Greek letters are used in its logo. 


\section{Conclusion}

This paper has presented a personal recollection of events over the period from the early 1990s to 2005 in relation to the development of a MSS community. It covers periods where there was an organised, membership-based community (the MSA) and other times when there was no such organised community and collaboration was more ad hoc. A second paper will subsequently be prepared to continue the narrative from 2005, exploring the achievements of sigma as a CETL until 2010 and beyond with participation in the National HE STEM Programme and ultimately the development of the sigma network as a self-sustaining community of practice.

\section{References}

Barnard, T. and Saunders, P., 1994. Superior sums that don't add up to much. The Guardian. 28 December 1994.

Beveridge, I. and Bhanot, R., 1994. An examination of maths support in further and higher education. Mathematics Support Newsletter, 1, p.13. Available at http://www.sigma-network.ac.uk/wpcontent/uploads/2018/11/MSA-Newsletter-1-Spring-1994.pdf [Accessed 4 June 2020].

Bowers, D., 1994. Maths workshops do exist. Mathematics Support Newsletter, 1, pp.2-3. Available at $\quad$ http://www.sigma-network.ac.uk/wp-content/uploads/2018/11/MSA-Newsletter-1-Spring1994.pdf [Accessed 4 June 2020].

Dzator, M. and Dzator, J., 2020. The impact of Mathematics and Statistics Support at the Academic Learning Centre, Central Queensland University. Teaching Mathematics and Its Applications, 39(1), pp.13-28.

Fuller, M., 2002. The role of Mathematics Learning Centres in engineering education. European Journal of Engineering Education, 27(3), pp.241-247.

Grace, J., 2016. Fluidised bed catalytic reactors. In: Z. Onsan and A. Avci, eds. Multiphase Catalytic Reactors. New Jersey: Wiley. pp.80-96.

Hawkes, T. and Savage, M., 2000. Measuring the mathematics problem. London: The Engineering Council.

Hymas, C., 1994. Engineers unable to bridge the maths gap. The Sunday Times. 20 November 1994.

Kent, P., Ramsden, P. and Wood, J., 1996. Maths support at Imperial College. Mathematics Support Newsletter, 4\&5, pp.10-11. Available at http://www.sigma-network.ac.uk/wpcontent/uploads/2018/11/MSA-Newsletter-45-Summer-1996.pdf [Accessed 4 June 2020].

Lane, J., 1994. Conference Proceedings. Mathematics Support Newsletter, 1, pp.14-16. Available at $\quad$ http://www.sigma-network.ac.uk/wp-content/uploads/2018/11/MSA-Newsletter-1-Spring1994.pdf [Accessed 4 June 2020].

Lawson, D., Croft, T. and Halpin, M., 2003. Good practice in the provision of mathematics support centres. $2^{\text {nd }}$ edition. Birmingham: LTSN MSOR Network.

Lawson, D., Grove, M. and Croft, T., 2019. The evolution of mathematics support: A literature review. International Journal of Mathematical Education in Science and Technology. DOI: 10.1080/0020739X.2019.1662120. 
Lawson, D., Halpin, M. and Croft, T. 2001. After the diagnostic test - what next? Evaluating the effectiveness of mathematics support centres. Part 1. MSOR Connections, 1(3), pp.19-23.

Lawson, D., Halpin, M. and Croft, T. 2002. After the diagnostic test - what next? Evaluating the effectiveness of mathematics support centres. Part 2. MSOR Connections, 2(1), pp.23-26.

LMS, IMA and RSS, 1995. Tackling the Mathematics Problem. A joint report of the London Mathematical Society, the Institute of Mathematics and Its Applications and the Royal Statistical Society. London: LMS.

Ramsden, P., 2012. A poor policy, poorly managed leaves little to show for $£ 315 \mathrm{~m}$. Times Higher Education. 15 March 2012.

Samuels, P., 1995. Maths Support Handbook, Mathematics Support Newsletter, 3, p.22. Available at $\quad$ http://www.sigma-network.ac.uk/wp-content/uploads/2018/11/MSA-Newsletter-3-Summer1995.pdf [Accessed 4 June 2020].

SQW, 2011. Summative evaluation of the CETL programme. Report for HEFCE. Available at: https://dera.ioe.ac.uk/13215/1/rd11 11.pdf [Accessed 4 June 2020].

Sutherland, R. and Pozzi, S., 1995. The changing mathematical backgrounds of undergraduate engineers. London: The Engineering Council. 